ISSN 1112-9867

Available online at

http://www.jfas.info

\title{
PARTICIPATION OF PEOPLE IN WASTE SOURCE SEPARATION PROGRAM
}

\author{
F. Razavian ${ }^{1}$, B. Khoshmanesh ${ }^{1}$ and S. Izadyar ${ }^{1, *}$ \\ ${ }^{1}$ Environment department of Islamic Azad University, Parand branch
}

Published online: 19 June 2016

\begin{abstract}
One of the basic problems of current cities is solid waste and its correct management. Solid waste material is the unavoidable product of routine life of human being. These wastes affect the quality and quantity of life in the present era. Increased population, development, human activities and shortage of resources have caused the solid waste management a necessity. Waste reduction management and its separation at source are performed with the citizens' participation. The present study aimed to evaluate the waste source separation and determine the participation of citizens in Azimie of Karaj city in Alborz province, Iran.

This study is questionnaire based and to achieve the study purpose, question-based questionnaires are distributed randomly among 100 citizens of Azimieh. The data were analyzed. Based on the results of study, in separation at source activity, $70 \%$ of people participated and the highest participation was via media and teachers. $100 \%$ of subjects were inclined to participate in this program. The effect of this plan was $90 \%$ and effectiveness of this plan from economic, social and environmental aspects was high.
\end{abstract}

Keywords: Waste, Separation at source, People participation, Azimie.

Author Correspondence, e-mail: sabaizadyar@yahoo.com

doi: http://dx.doi.org/10.4314/jfas.v8i2s.148

Journal of Fundamental and Applied Sciences is licensed under a Creative Commons Attribution-NonCommercial 4.0

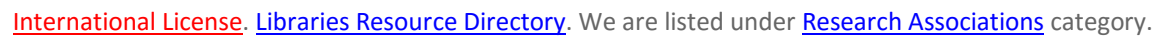




\section{INTRODUCTION}

The increase of population and development of cities obliged the managers and urban planners to provide plans for logical development of cities and fulfill the needs of citizens. Citizens as owners of city to improve urban environment health and implementation of plans play important role and the lack of collaboration hinders any plan. One of the most important problems of new era involving people and generally the countries around the world is waste issue and it is increasing with the population increase. In case of the lack of correct management, the wealth of country is wasted and it affects environment and human health and its outcomes are not described. Waste recycle is one of the most efficient solutions to reduce costs in separation at source and improvement of environmental and health condition in cities and is only possible via serious participation of citizens (3). At first, we should define the features of citizens' participation in this regard and awareness of the execution of recycle plans is of great importance. A few studies have been conducted regarding assessment, citizens' participation in waste recycle. The role of participation in development is considered an important principle. Development should be performed by human resources in society. Today, human resources and relevant issues are one of the main principles of development theories. The present study aimed to evaluate the awareness of citizens of Azimie region of the role of waste separation in urban waste management and their commitment to this problem. By this study, the following goals are achieved:

1- Education and increasing public awareness in reduction of waste

2- Attracting the citizens participation for waste disposal

3- Informing regarding the benefits of recycle materials

4- Training and encouraging the public to separate dry and wet waste (Firoozabadi and Sodayizade, 2008).

\section{Generalities}

\section{Waste definition}

In routine life, different wastes are generated as waste and wastewater. In this division, any solid, gas or liquid (except wastewater) resulting directly or indirectly from human activity is considered waste. The generated sewage is wastewater. The waste is divided into different types in terms of sources (2). The waste classification is as follows:

\section{1-1-1 Ordinary waste}


1-1-2 Medical waste (hospital)

1-1-3 Agriculture waste

1-1-4 Industrial waste

1-1-5 Special waste (Ziksazy and Jensi, 2011)

\section{Urban waste management}

Waste management is one of the most important concerns of human communities. The increase of waste on one hand and their variety on the other hand have increased the complexity of conditions and collection and waste disposal. Wide progress of technology and sciences in various fields as chemistry, physic, medicine, etc. has increased dangerous waste even in domestic waste. Today, traditional waste disposal systems can not fulfill the needs and can not avoid the environmental pollution of different chemical, microbial, radioactive waste. Despite the problems in approving waste management law, this rule is one of the great steps to improve the waste management condition in the country. Based on this rule, municipalities were considered as the organization managing domestic waste for the first time. It seems that municipalities' actions are not effective without the participation of people and other relevant institutes (Vivian).

\section{The global condition of urban solid waste management}

The urban solid waste consists of tens of different compositions requiring correct management in all fields as storage, collection to disposal. Urban waste management has received much attention by international communities and countries namely developed countries and some of the factors are as follows:

Urban waste disposal leads to severe environmental pollution and water (underground and potable water), air and soil pollution.

-Municipality solid waste is one of the most important factors of greenhouse gas emission with negative influence on global warming.

- A part of waste can be recycled. This means that by their re-use, energy and raw materials are saved.

- A part of waste is recycled. It means that by their recycling with saving in energy consumption, value-add of waste is increase.

- Energy of wastes is cleaner than the energy of fossil fuels.

- By producing energy from waste, total or part of waste management costs are returned (5). 
Now, all countries around the world focus on reduction and prevention of waste at source. Recycle of solid waste is another priority. The maximum recycle of materials and energy production is in the next rank. The reduction of landfill is of great importance. The following Figures show the hierarchy of waste management, problems of greenhouse gas emission, waste management in Europe and US (5).

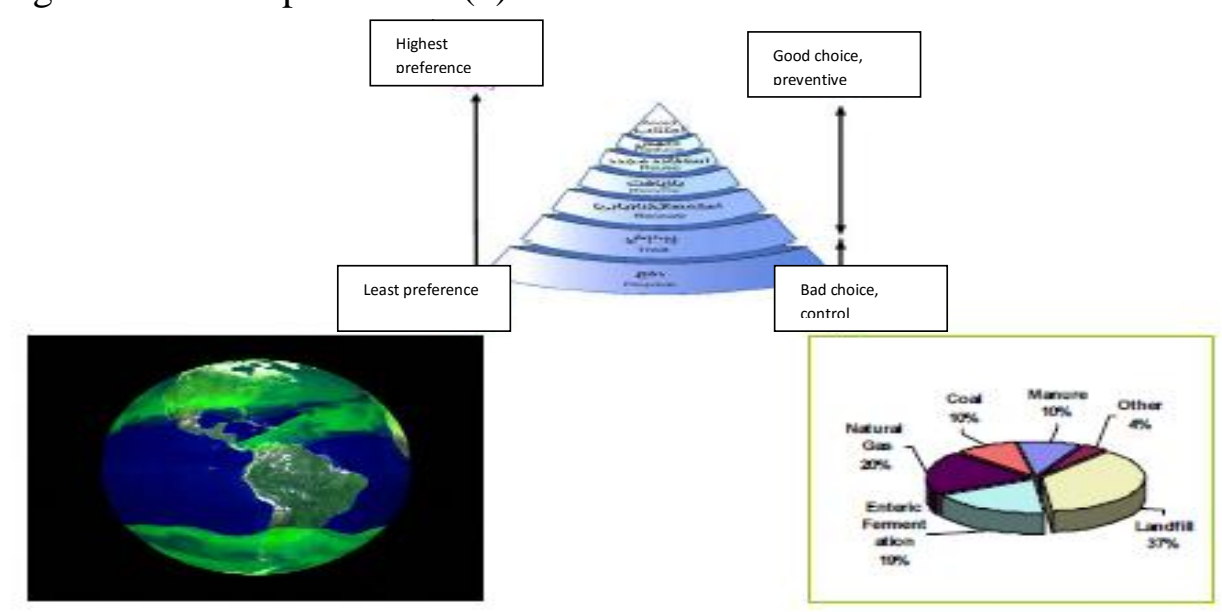

Fig.1. Hierarchy of solid waste management and share of landfill of methane concentration in atmosphere (5)

\section{Separation at source}

Waste disposal is one of the problems of the present world namely in the third world and developing countries. Most of the wastes are recycled in nature like food waste. Some of them as glass and rubber are not decomposed and others are recycled after a long time. One of the issues considered as waste plans for the countries is waste separation at source. This increases health principles in the goods generated from recycled materials. On the other hand, great amount of waste disposal is eliminated. In our country, waste disposal is delegated to the deputy of urban services of municipalities. However, its recycle is performed by recycle organization. All over the world, this is one directly by an institute. In Iran, $80 \%$ of waste disposal is delegated to recycle organization and in other small or big cities, many institutes follow this activity. It seems that if waste reduction is not performed by people, by management of one or some institutes, we cannot reduce the waste considerably (11).

\section{People participation in urban services management}

In the present complex world, urban services management with relationship with all individual and collective aspects of citizens' life is one of the important issues of urban dwellers. The good 
management of urban services provides the ground in which citizens can improve their life style. Good management of urban services is actualized if the citizens participate in it in decisions and policies and planning activities. Comprehensive definition of participation is emotional involvement of people in group situations motivating them to help each other to achieve group goals. The strategic model of participation is not similar in different countries, cities or townships. There is no great distance between traditional participation and modern participation and it is included in the geographical domain of a municipality region (4). The participation of citizens in urban services is divided into the followings generally:

1- Awareness of decisions and plans

2- Participation in managerial decisions of plans

3- Participation in funding of plans

4- Participation in providing man power

5- Participation in execution of plans

Citizens' participation in urban services is fulfilled if the city dwellers are turned into a citizen from an individual living in a place called city. The citizen observing all above items can achieve development participation, participation with integrated, comprehensive, dynamic social process correlated with motivation and involved in all stages of urban service development (9).

\section{The effective factors on participation of people in separation at source activities}

Flow diagram NO. 1 indicates effective factors on participation amount. As shown in the Figure, effective factors on people participation are awareness via training, attitude change and creating motivation and then action to participation. The first step in attracting people participation is awareness and training. The scientists and experts believe that one of the ways to fight against environmental issues is wide activities in cultural aspects as via public training, families are familiar with the harmful effects of waste and their environmental knowledge regarding waste and risks is increased (7). 


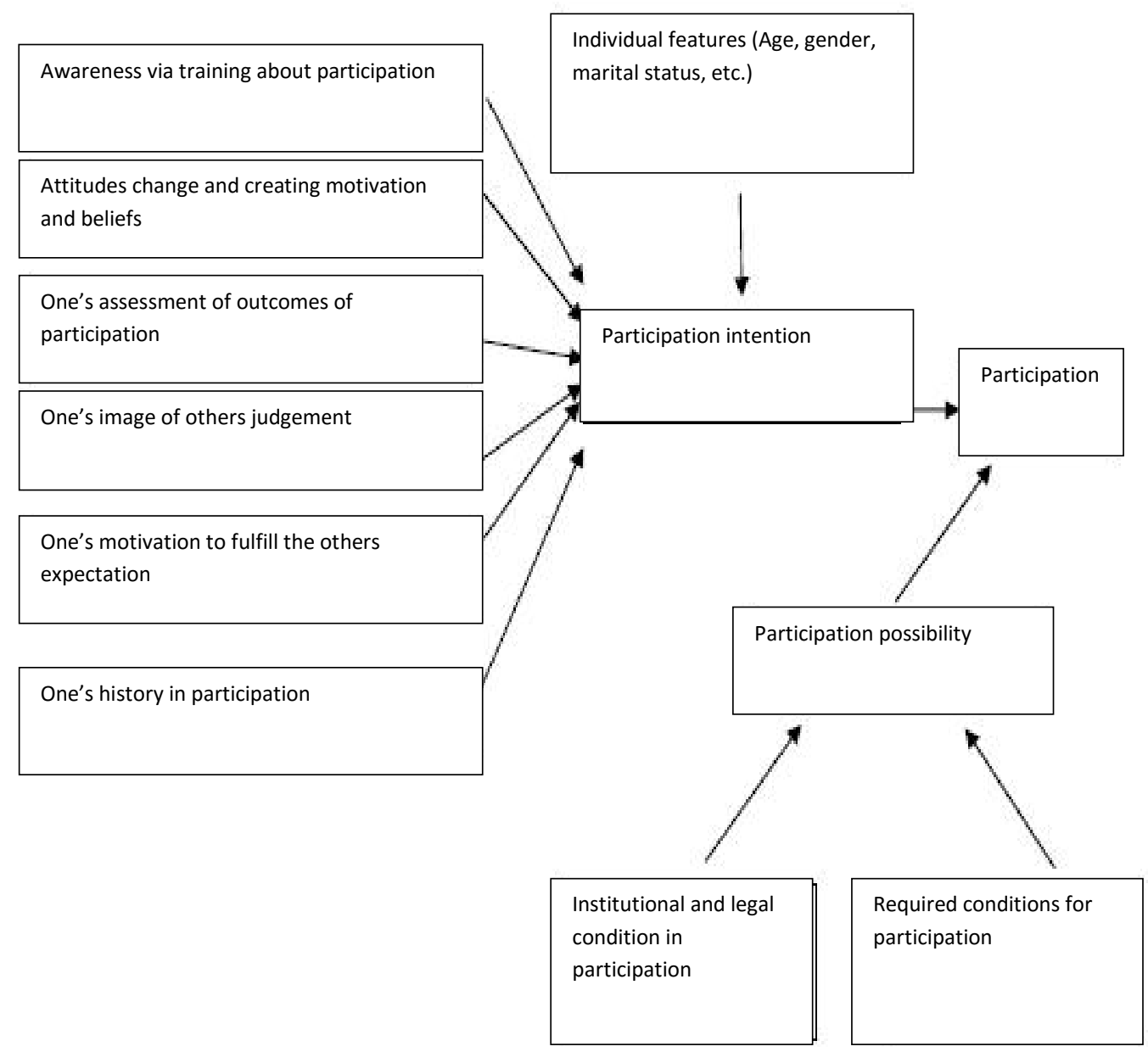

Fig.2. Effective factors on participation of people (7)

\section{The introduction of study area}

Azimihe is the name of a township in north east of Karaj city in Alborz province, Iran. This part of Karaj city in located in Alborz. Thus, it has steep surface. This township was recognized as Pargirak in the past. With some springs, this area was considered by citizens. In recent years, the citizens were increased rapidly. This region consists of some squares including Asbi, Mehran, Golestan, Baharestan, Besat squares. One of the attractions of Azimie is Noor Mountain, Karaj roof and various restaurants in this area. There is a beautiful park called Iranzamin in this area. The most famous high building in Azimie is Sarv building. The biggest building in this area is Atlas located in Besat square. Due to construction and lorries in this area, high gradient in some parts are some weaknesses of this area. Another weakness of this area is its proximity with old texture of Islamabad as improved in renovation plans of old textures. This area is called 
Moradabad valley in old books and has great view compared to all townships of Karaj. This region is located in range gradient and has good climate and it is turned into a tourism area gradually. The recreational park was established since 2010 beside Asbi square and with renovation of this old square increased its attractions and food centers in the main street (Dr. Shariati street) of this township are some true examples. Some of the cultural and sport places in this region are artificial grass football field of Chabardar, Yadavaran and Kosar pools and also observatory in Islamabad valleys. Also traffic organization of Alborz province is located in Taleghani square of this township, medical system, deputy of health, Radio Alborz, Gas office, justice court, office of industry, mines and fruit and vegetable centers are located in the street leading to Noor valley.

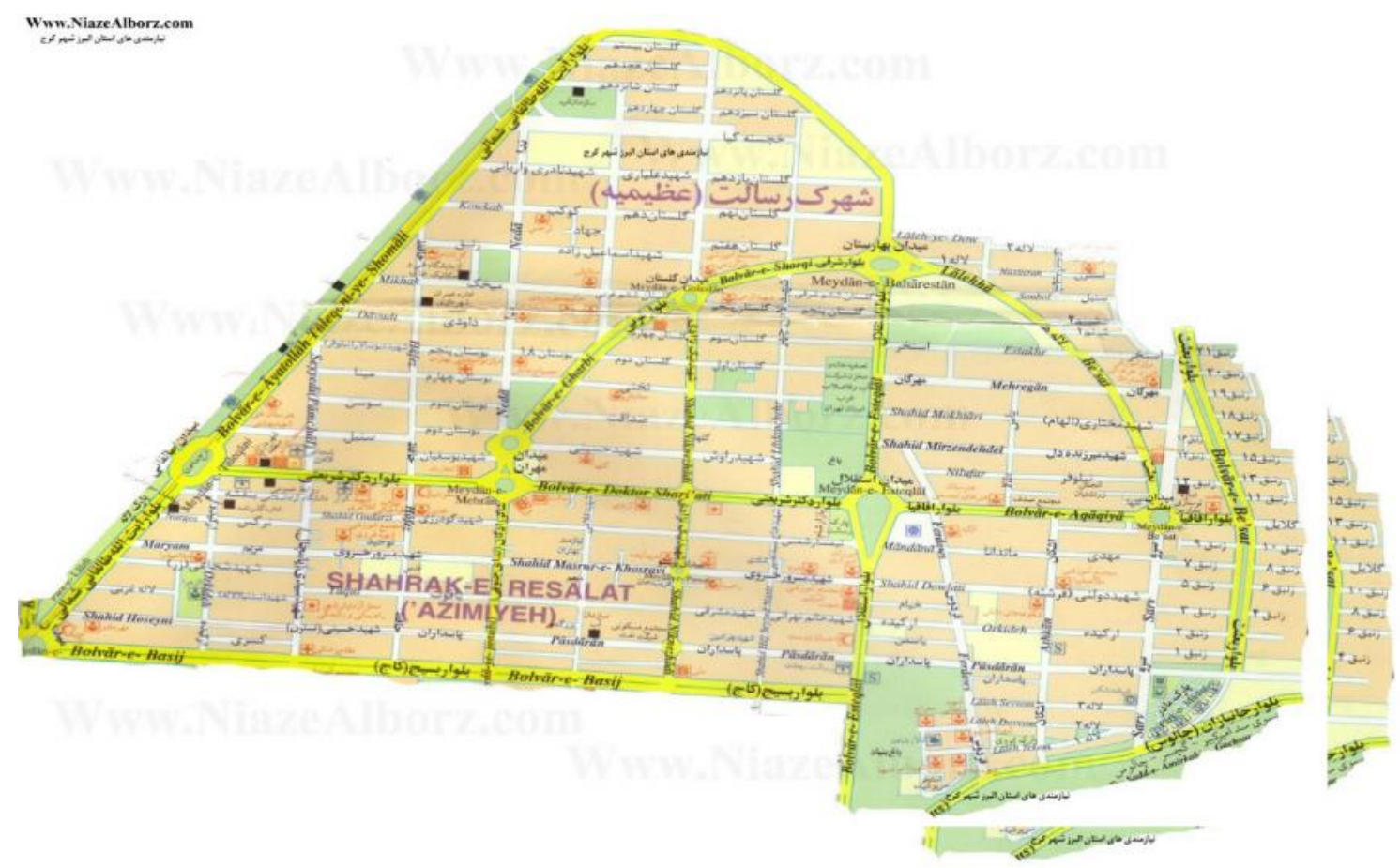

Fig.3. General view of Azimie region 
2. Methodology

To conduct the present study, researcher-built questionnaire with 17 items was provided and after acquiring the experts opinion, was completed by 100 residents of Azimie in Karaj randomly. The relevant reports were investigated and field studies were conducted. The results were analyzed. It is worth to mention that of total respondents, there were $33 \%$ men and $66 \%$ women.

\section{Results}

By investigation of questionnaires, the following results were achieved:

Of total respondents, there were $60 \%$ women and $40 \%$ men, $10 \%$ were less than 20 years, $10 \%$ $20-30$ years, $20 \%$ were $30-40$ years, $40 \%$ were $40-50$ years and $20 \%$ above 50 years. $15 \%$ of respondents were below diploma, 20\% Diploma, 20\% BA, 45\% above levels. $15 \%$ had income less than 1 million, $30 \%$ with the income of 2 million, 25\% had 2-3 millions, 30\% above 30 million. $57 \%$ were employees, $36 \%$ businessmen and $7 \%$ were students.

\section{Discussion}

\section{Familiarity of the respondents with separation at source}

$70 \%$ of respondents were familiar with separation at source activity and $30 \%$ were not familiar with separation at source plan.

\section{The familiarity of respondents with separation at source activity}

Respondents were familiar $20 \%$ via media, $40 \%$ via teachers, $20 \%$ via personal studies, $20 \%$ via other items.

\section{Informing people regarding waste separation}

$40 \%$ of respondents had average information of waste separation. 35\% had good information, $15 \%$ no information and $15 \%$ were others.

\section{The purpose of separation at source}

$20 \%$ considered recycle, $25 \%$ energy saving, $40 \%$ environment health protection and $15 \%$ considered all items of the goals of separation at source.

\section{Inclination of people to do participation in separation at source activities}

$100 \%$ of people were inclined to do participation in separation at source plans.

\section{The effect and people participation in this plan}

$90 \%$ of people had good participation, $10 \%$ average participation.

\section{The type of wastes in separation plan}

$50 \%$ of wastes were dry, $20 \%$ wet waste, $20 \%$ indefinite and $10 \%$ other. 


\section{The money to deliver waste}

$20 \%$ educational packages, $20 \%$ free rubbish bin, $50 \%$ cash and $10 \%$ others.

\section{The reasons of failure of Iran in execution of separation plan}

$15 \%$ reported lack of informing, $60 \%$ no collaboration, $15 \%$ no motivation and $10 \%$ others.

\section{Showing positive environmental, economic and social effects of separation at source plan}

$100 \%$ reported that separation at source had positive effect.

\section{The priority of wastes}

$30 \%$ as rubber and glass, $30 \%$ paper, $15 \%$ electronic waste and $25 \%$ all items.

\section{The effectiveness of separation at source on economy, health and environment}

According to people, the effectiveness of this plan was 10\%, 20\% average, $70 \%$ high and $10 \%$ others. $90 \%$ of people had good participation and $10 \%$ had average participation.

3-7 The type of wastes in separation activity

$50 \%$ of wastes were dry, $20 \%$ wet, $20 \%$ indefinite and $10 \%$ others.

3-8 The received money to delivery waste

$20 \%$ received educational packages, $20 \%$ free rubbish bin, $50 \%$ cash and $10 \%$ others.

3-9 The reasons of failure of Iran in separation activity

$15 \%$ reported no informing, $60 \%$ no collaboration, $15 \%$ no motivation and $10 \%$ others.

3-10 Showing positive environmental, economic and social effects of separation at source $100 \%$ reported that separation at source had positive effects.

3-11 The priority order of wastes

$30 \%$ as rubber and glass, $30 \%$ paper, $15 \%$ electronic waste and $25 \%$ others.

3-12 The effectiveness of separation at source on economy, health and environment The effectiveness of this plan is $10 \%, 20 \%$ average, $70 \%$ high and $10 \%$ others.

\section{REFERENCES}

[1] Hushmand Firoozabadi F, SodayizadeH. 2008. The role of education, culture and social participation in waste management of Shiraz city. Conference of planning and environment management.

[2] Raisisarasiab Abdollah M. 2013. The evaluation of awareness and participation of Ahvazi citizens in materials recycle. 
[3] Vahid, Fereidoon; Niazi, M. 2014. A review of the relationship between family structure and social participation in Kashan city. Social sciences. N0. 73

[4] Navabakhsh, Mehrdad; Naeimi, Masume. 2001. Explanation of effective social factors onattracting participation of citizens on waste disposal and separation

[5] Mirtabar, Mehdi. 2006. Waste, threat or opportunity, planning and environment management conference

[6] Ziksazy, Mehrouz; Jensi, Zhra. 2011. The study of waste separation source plan. Case study of households of small town of Isfahan in Gilan province. Conference of planning and environment management

[7] Ballestero, E. Compromise programming: A utility-based linear-quadratic composite metric from the trade-off between achievement and balanced (non-corner) solutions. European Journal of Operational Research. 182(3): 1990-2003

[8] Vivian, T. Evaluations of existing waste recycling methods: A Hong Kong study. 41: 16491660

[9] Reis E. Behavioral Determinants of Household Recycling Participation: The Portuguese Case. Environment and Behavior. 36(4): 505-540

[10] Manoliadis O. Development of ecological indicators - a methodological framework using compromise programming. Ecological Indicators. 2(1-2): 169-176

[11] Borisova P. Modernization of Municipal Solid Waste Management in Bulgaria. Institutefor Environmental Strategies.

How to cite this article:

Razavian F, Khoshmanesh B, Izadyar S. Participation of people in waste source separation program. J. Fundam. Appl. Sci., 2016, 8(2S), 1017-1025. 